\title{
SOCIO-PSYCHOLOGICAL FACTORS OF PERSONAL GROWTH IN FAMILY CONDITIONS
}

\section{Bila I. N.}

\section{INTRODUCTION}

The first and main "school" of socialization, social adaptation of the individual is a family. The family is a microsystem of society, which acts as the main agent of the influence on the personality that promotes knowledge and determines one or another of its qualities and characteristics. All components of the imdividual's structure, his abilities (motivationally-volitional, personality-value, operational-activity, cognitive-creative) can develop successfully only if there is a developing space, in particular, a family.

According to E. Bern, human destiny is largely driven by "parent programming, scripting" - the formation of a scenario, a plan of life in childhood under the influence of parents. After all, children tend to copy the behavior of those with whom they are in the closest contact. It is partly a deliberate attempt to behave in the same way as behaving meaningful adults, partly unconscious imitation, which is one aspect of identification with another. In this regard, it is important to note that children learn from their parents by certain ways of behavior, not only by mastering the rules that they directly report, but also by observing the model (examples) of behavior existing in the parent's relationship.

Parental love is a huge and irreplaceable source of spiritual development of the child, emotions, moral qualities, positive perception of the world, self-confidence; condition and inexhaustible source of sensitivity, care, respect for people. Communication in an atmosphere of intimacy, love, trust, care for each other has a strong influence on the child's psyche and further provides a wide area for the emotional experiences of the child, the realization of his needs, satisfaction of interests, and thus become for him the true school of social relations and the arena of self-realization. A child who has not received parental love grows hostile, angry, stubborn to the experiences of other people, brave, unproductive in a group of peers, sometimes - closed, too shy and uncertain. 
Messengers, which parents repeat repeatedly, are captured in subconscious ordinances and determine future value orientations, abilities. Communicating with adults who bring up a child is a source for him, not comparable to anything else bright, personally addressed to his influences, stimuli and patterns. It dismantles the axiomatic nature of the thesis of L.S. Vyhotsky that all higher mental functions of a person are primarily formed as external, that is, those in the implementation of which involves not only one, but at least two entities. And only gradually they become internal, turning from "interpsychic" into "intrapsychic". The development of the views of L.S. Vyhotsky led to the creation of an original concept of child development, in which the development of the child is understood as the process of children's appropriation of the socio-historical experience gained by previous generations of mankind (O.M. Zaporozhets', O.M. Leontiev, D.B. Elkonin) Proceeding from this, the promising way of forming personal reference points that determine the vital "trajectory", the vector of personality development is family interaction, communication in the family, which declares the democratic style of education, encouragement of activity, curiosity, and creativity of the child.

In this case, it is important that the strengthening of the educational potential of adults, the positive development of mutual influence in the family, which manifests itself in the growth of the level of pedagogical literacy of parents and affects the development, behavior of the child, its successful social adaptation.

\section{Family-centeredness in the development of the child's personality}

The child born to nature, endowed with the possibility of individual development in the social and cultural context of the era. The main characteristic of the such context is the concept of the social situation of development is developed by L.S. Vyhotsky. It is based on the child's experience of the environment of his residence and himself in this environment. If these experiences are positive, the environment has a developmental effect and in it is possible implementation and development of abilities of the child.

In the effective contact of the child with the surrounding world, in the process of gradual assimilation of the achievements of the previous historical development of mankind, carried out in the course of education, are transformed into diverse and advanced abilities (L.S. Vyhotsky, 
V.V. Davydov, H.S. Kostiuk , B.M. Teplov, S.L. Rubinshein, etc.). In a developing educational environment, the space of social interaction, the child finds incentives for self-education and self-development precisely at the initial stage of ontogenesis, which is crucial for the formation of personality, the formation of abilities. After all, in the preschool age, the person "is produced" (V.V. Davydov) is precisely in the creation of such an environment that would provide the child with developmental interaction, mastering the social space of human relationships, the special role of which is given to the "adult child" community.

As is known, in 1912 in Kyiv I.O. Sikorsky was created the world's first Institute of Child Psychology. Observation of development in early childhood made it possible for Sikorsky I.O. to conclude that "the numerous irregularities in the character of man and in his abilities are beginning in the early days, in the first months and years of life, and lead to persistent features of the mental composition of a future adult. Such disadvantages, which were considered congenital, and therefore it was considered that it is impossible to eliminate them, in the opinion of the professor, are accessible to the medical and pedagogical influence"1.

These findings have become the impetus for other studies in the field of children's, social psychology, family psychology. Thus, in particular, the problem of family education is devoted to a whole range of works and researches of native and foreign scholars (D. Baumring, E. Bern, P.P. Blonsky, V.M. Drujynin, S.O. Ladyvir, M.I. Lisin, P.F. Lesgaft, A.E Lichko, Dzh. Medina, V. Satir, A.S. Spivakovs'ka, V.O. Sukhomlyns'ky, E.H. Eyedemiller, T.M. Yablons'ka, etc. Psychologists have revealed psychological peculiarities relationships in the family, described the child-parents relationship.

The main thesis in the most studies of the field of social work in the family, family psychology can be formulated as such: "The nature of the relationship in the family affects the development of the child, his later life". In general, the negative factors of family education are: inadequate influence of the factors of the material order: the priority of material wellbeing over the realization of the spiritual needs of the child; lack of spirituality of parents, lack of desire for the spiritual development of

\footnotetext{
Ponomareva-Semenova R.A. Methodological aspect of developing a psychological model of an extraordinary personality // Current problems of psychology: Volume 6. Gifted personality: search, development, help. (collection of scientific works). / Under the editorship of S.D. Maximenko. - K. "BONA MENTE", 2002. Vip. 3. (Part 1) - P. 226-236.
} 
children; authoritarianism or parental liberalism; immoral style and tone of family relationships; absence in the family of a normal psychological climate and pedagogical culture of communication; illiteracy in the psychological and pedagogical relation (lack of purposefulness of education, unprincipled, contradictory in the application of methods of education, physical punishment, infliction of children of severe moral suffering), etc. For children deprived of favorable family conditions, strong and unequivocal evidence of parental love, confidential communication, psychophysiological and psychosomatic disorders, neurotic disorders, difficulties in communication and mental activity are much more often observed. Communication creates a feeling of emotional well-being, warmth and comfort in a new and unfamiliar world. These feelings are like fertile rains that irrigate the delicate shoots of the first knowledge and skills of the child. Studies show that in conditions of "drought" of human feelings, in the absence of communication, these sprouts develop poorly, and sometimes completely fade ${ }^{2}$.

Thus, as a result of the "environmental" research program, it was found out by V.M. Drujynin that the family environment develops the creative abilities (ability to intellectual creativity), non-verbal intelligence and partial abilities (memory, attention, sensomotorics). In the work of O.L. Hryhorenko and B.I. Kochubey, it is proved that the magnitude of the genetic predisposition of most personal qualities (excluding temperament) is significantly downward from the indicators of imitation of general and special abilities, and the level of development of verbal and non-verbal creativity (general creative ability) depends from the breadth of the circle of communication and the presence in the family of a democratic style of education ${ }^{3}$.

It is worth noting that the style of education is understood as a certain strategy of education, as a combination of different behaviors of parents, which in different situations and at different times will manifest itself to a greater or lesser extent. This approach allows you to build a peculiar profile of parenting behavior that reflects the most characteristic style of education, both in the individual case for a particular parent, and for a group of parents of children of a certain age.

\footnotetext{
${ }^{2}$ Subbotsky Ye.V. The child opens the world: Kn. for the child's teacher. the garden / E.V. Subbotsky. - M. : Enlightenment. - $1991-207$ p.

${ }^{3}$ Druzhynin V.N. Psychological abilities / V.N. Druzhynin. - St. Petersburg: Publishing House "Peter", 2000. - 368 p. : (Series of "Masters of Psychology").
} 
Nowadays, scientists have proposed different classifications of childparents relationships, styles of education. In our opinion, Diana Baumrind's classificstion of the parenting styles are based on two pillars of education, each of which is on the continuum: sensitivity is the degree of parents' response to their children with support, warmth and compassion. and demanding that takes into account the degree of parents' desire to control the behavior of the child. Taking into account these characteristics creates four verified large-scale study of the styles of upbringing children. Namely:

Authoritarian (over hard) - insensitivity plus demanding. For these parents, it is very important to establish authority over their children, and the children of these parents often fear them. They do not try to explain their rules and are completely devoid of warmth and benevolence.

Covetous (too soft) - sensitivity plus non-necessity. These parents love their children very much, but they are not able to establish and enforce the rules. Subsequently, they avoid confrontations and occasionally demand compliance with family rules. These parents are often confused with the task of bringing up children.

Neglect (too detached) - insensitivity plus indifference. These parents take little care of their children and do not take part in their daily lives, providing only basic care.

Authority (suitable) - sensitivity plus demanding. These parents are demanding, but they care a lot about their children. They explain their rules and encourage them to respond to them, encourage self-reliance, but ensure that children adhere to family values. These parents are usually inclined to have good communication skills with their children ${ }^{4}$.

On the decisive significance of family education in the development of personality, from the birth of a child to her admission to school, also emphasized P.F. Leshaft, and proposed his classification of the parents' position in relation to children:

27. Parents do not pay attention to children, humiliate, ignore them. In such families, children often grow up hypocritical, false, they often have a low intelligence or a delay in mental development.

28. Parents constantly admire their children, consider them a model of perfection. Children often grow selfish, superficial, self-confident.

\footnotetext{
${ }^{4}$ Medina John. Rules for the Development of the Child's Brain / John Medina. - K. : Our format. 2015.
} 
29. Harmonious relationships built on love and respect. Children are distinguished by kindness and depth of thinking, aspiration for knowledge.

30. Parents are constantly dissatisfied with the child, criticize and condemn her. The child grows an1noyingly, emotionally unstable.

31. Parents excessively corrupting and protecting the child, it grows lazy, socially immature.

32. Parents whose behavior is affected by financial difficulties. Their children grow up with a pessimistic attitude towards the outside world ${ }^{5}$.

Incorrect parenting, improper parenting provokes the appearance of negative traits of character, its accentuation. According to scientists (A.E. Lichko, K. Leonhard, V.V. Yustyts'ky, E.H. Eyedemiller), there is a pattern between the type of accentuation of nature and the kind of incorrect education, from the position of the styles of family upbringing. As regards the thought of children about the style parenting, then research has shown that children generally like the inductive style of correction, seasoned with a periodic demonstration of strength. Children between the ages of four and nine, as opposed to adolescents, hate permissiveness. Parents whose rules are derived from sensitive perception, and motivations are constantly explained, ultimately perceived as smart and just, and not capricious and despotic, they are more likely to receive obedience from their children instead of loyal resistance ${ }^{6}$.

The experiment of A. Bandura "Lessons of Clown Bobo" proved to be valuable, in which he showed the role of learning through observation and proved that children (and adults) learn a lot by observing the behavior of others. This can also be a positive phenomenon. For example, Mexican "soap opera", whose heroes are fond of books, and then ask viewers to enroll in the reader's circle, to increase the level of readability throughout the country. The discovery of A. Bandura became an extraordinary weapon of mass training and reaffirmed the idea of the social situation of development.

It is exactly family interaction, "mental stimulation" that occurs when communicating and co-operative activities of the child and adult is a decisive environmental factor in the development of children's intelligence. For example, the results of the study conducted by V.M. Drujynin showed that those who received experimental support from the emotional support better solved test tasks, and the presence or absence of

\footnotetext{
${ }^{5}$ Leshaft P.F. Family medicine peder / P.F. Leshaft. - Moscow: Pedagogics, $2014-224$ p.

${ }^{6}$ Medina John. Rules for the Development of the Child's Brain / John Medina. - K. : Our format. 2015.
} 
control over the behavior of the child does not significantly affect the measurement of intelligence. That is, not cognitive-behavioral control, but emotional support, the creation of a certain emotional environment affects the outcome of mental activity of the child. In the absence of control of behavior and emotional support, smart children begin to fear failure. On the contrary, with a high control of behavior and emotional support (dominant hyperprotection), low-intellectual children develop motivation for success. With the preservation of emotional support and the lack of rigorous control on the part of the adult raises intellectual productivity ${ }^{7}$.

All this corresponds to the ideas of L.S. Vyhotsky about the "zone of immediate development": any supportive intervention of an adult improves the result of the task. In general, the influence of communication on the mental development of the child occurs due to: 1) the favorable "objective" qualities of the adult, which is combined with its properties as the subject of communication; 2) enrichment of the adult experience of children; 3 ) direct setting of adults tasks that require the child to master new knowledge, skills and abilities; 4) the supporting effect of opinions and assessments of an adult; 5) opportunities for the child to draw in communicating patterns of actions and actions of adults; 6) favorable conditions for children to disclose their creative, original beginning ${ }^{8}$.

According to M.I. Lisin, the three groups of facts prove the decisive role of communication in the general mental development of the child, in particular: 1) the study of children, "Mowgli" (children who have grown in isolation from society have a deep and irreversible underdevelopment), 2) study of the nature and causes of hospitalization (deviations associated with the lack of maternal care, in particular, children who are brought up in orphanages), and 3) the direct manifestation of the influence of communication on mental development in forming experiments.

Confirmation is also the result of the study, obtained by Skills and his staff in the 1930's in one of the boarding houses for mentally retarded children in Iowa. In total, the group consisted of $25 \mathrm{kids}$, these children all the time lay in their beds and were separated from each other by curtains. It has been noticed that children who grew up in such conditions, as a rule, never reach the normal level of intellectual adaptation, the majority remains in clinics for mentally disabled. Skills took 13 children and placed

\footnotetext{
${ }^{7}$ Druzhynin V.N. Psychological studies / V. Druzhynin. - Moscow: “KSP”, 1996. - 160 p.

${ }^{8}$ Lisina M.I. Problems of ontogenesis of communication / M.I. Lisin // Scientific research. Institute of General and Pedagogical Psychology Acad. ped Sciences of the USSR. - Moscow: Pedagogics, 1986. - 144 p.
} 
in a mortgage for mentally disabled women. Women were very emotionally embraced by babies, looked after them, talked and caressed. Subsequently, children began to develop rapidly, their intellect reached norms, and practically all of them in the future became full members of society (four received higher education) ${ }^{9}$.

Communication, according to scientists, is just as necessary for the child as food. A kid who receives a good nutrition and good medical care but is deprived of constant contacts with adults develops not only mentally, but physically. It is noted that when children are brought up in a kindergarten, where the communication of a child with an adult is minimized, since one educator has more than 10 children, they are lagging behind their peers who are raised in the family, in intellectual and sensory-motor development [7]. It was found that for the survival and development of the child, it is necessary that they play with her, spoken several times a day. Human communication is vital to the child. Familiar family physician Virginia Satir recommends hugging a child several times a day, arguing that four hugs are needed for everyone just to survive, and for at least eight hugs a day ${ }^{10}$ !

It should also be emphasized that for the proper mental development of a small child, relations with the mother are of paramount importance (J. Boulby, R. Spitts, A. Freud and others). It is maternal love that gives the baby a sense of security, contributes to the development of the image of themselves and socialization. Lack of communication with her, endangers the child's life, impedes her physical and mental development. Thus, I.V. Dubrovina, A.H. Ruzskaya characterizing the portrait of a person formed in a child who was born from birth in conditions of maternal deprivation, points to her: an intellectual lag; the inability to enter into meaningful relationships with other people; lethargy of emotional reactions; aggressiveness; self-doubt and so on. In children who have experienced maternal deprivation, confidence in the world can only arise through emotional warmth of constant maternal care.

It is obvious that the influence of his father significantly affects the formation and development of the child's personality. In the process of education, the father instills important qualities for his children. For a boy, this is a man's dignity, a chivalrous attitude to a woman, the ability to take responsibility, ability to work. Father is an example for his son for

\footnotetext{
${ }^{9}$ Druzhynin V.N. Psychological studies / V. Druzhynin. - Moscow: "KSP”, 1996. - 160 p.

${ }^{10}$ Hippenreiter Y.B. Communicate with the child. How? / Y.B. Hippenreiter, - Moscow: CheRo, 2001.240 p.: il.
} 
imitation and greatly affects the formation of sexual identity. Boys copy the behavior and style of parenting their own, they have a certain scenario of their future life.

It is worth mentioning the results of the research of prenatal psychology. According to E. Bern, the role of the child can also be influenced by the situation of conception, he suggested that the situation be called "the embryonic setting" and recommended to analyze the circumstances of the birth of life. The attitude of parents to the process of conception also reflects on their attitude towards the child. If conception has occurred erroneously, it is likely that the attitude of the child will be appropriate. Based on his research, E. Bern concluded that there are "generic scenarios" that are formed up to five years. In his view, a person begins to live like a "loser" or "victor", grows "family pride" or "those who do not justify hope" $"$.

Similar conclusions were made by S. Hroff, proclaiming his concept of prenatal existence. He singled out four periods that are stored in the human subconscious, calling them basic prenatal matrices, each of which forms a strategy for the attitude toward the world to himself.

From the first minutes of the birth of a new life, parental love determines the life scenario, it is a huge and irreplaceable source of spiritual development of the child, emotions, moral qualities, positive perception of the world, self-confidence; condition and inexhaustible source of sensitivity, care, respect for other people in the future. Scientists emphasize that childhood, full of love, is enough for all the rest of life. A child who has not received parental love grows hostile, angry, stubborn to the experiences of other people, brave, unproductive in a group of peers, sometimes - closed, too shy and uncertain. A child who grew up in an atmosphere of excessive love, clutter, reverence and indulgence will soon develop the features of selfishness and egocentrism, of modesty, promiscuity, indifference and hypocrisy. If the family has no harmony of feelings, if the child is generally exposed to the effects of the immoral atmosphere, emotionally negative manifestations towards the child, then in such families the development of the child becomes more complicated, family education becomes an adverse factor in the formation of the child's personality, complicates the development of abilities child ${ }^{12}$.

\footnotetext{
${ }^{11}$ Bern E. Games in which people play // E. Bern - Exmo, 2003. - 576 p.

12 Schneider L.B. Family: Looking Back / L.B. Schneider. - SPb. : Peter, 2013. - 368 pp .: Il. - (Series of "Masters of Psychology").
} 
Well-known psychotherapist V.I. Harbuzov warns against the use of wrong education:

1. A-type education (rejection, emotional rejection) - the rejection of the individual characteristics of the child, combined with strict control, with the imperative imposing on her the only correct type of behavior. The type of upbringing A can be combined with lack of control and even full complacency.

2. B-type education (hyper-socializing) is expressed in the anxious and distrustful concentration of parents on the health status of the child, her social status among comrades, and especially in school, expecting success in education and future professional activities.

3. C-type education (egcentric) - cultivating the attention of all family members on the child, sometimes to the detriment of other children or family members.

An interesting classification of deviations in the styles of family education (which correlates the peculiarities of the formation of the personality of children and the styles of family education) offer A.E. Lichko and E.H. Eyedemiller:

Hypoprotection is characterized by a lack of burn and control. The child remains unattended. The non-inclusion of the child in the life of the family leads to an antisocial behavior because of the dissatisfaction with the need for love and recognition.

Dominant hyperprotection is manifested in increased, intense attention and care, excessive welfare and behavioral control, slips, bans and limitations. The child is not accustomed to autonomy and responsibility. This leads either to the reaction of emancipation, or to non-initiative, the inability to stand up for oneself.

Hyperprotection, the so-called upbringing of the "family idol". Parents seek to free the child from the slightest difficulty, indulge her desire, overwhelmingly adore and admire her successes and demand the same passion from others. The result of this upbringing is manifested in a high level of aspiration, aspiration for leadership, which can be combined with insufficient stubbornness and reliance on their strengths.

Emotional rejection - the child is burdened, her needs are ignored. Sometimes they are cruelly treated with her. Parents consider the child a burden and show general dissatisfaction with her. Often there is a hidden emotional exclusion: parents tend to veil the real attitude towards the child 
with increased care and attention to it. Such a style of education has the most negative impact on the development of the child (loss of love, loss of personality, love for "themselves").

It has been established that only a small part of the parent community is able to ensure the harmonious development of the child's individuality $(14.5 \%)$. In the majority of the same families, there was a tendency toward a partial parenting style (74.5\%), in which only the child's needs are partially met, their individual differences are not fully taken into account, and care for the development of defining properties for individuality manifests itself episodically. In a significant number of families, the focus was on the disharmonious development of the child's individuality $(11 \%)^{13}$.

This type of family includes families living below the poverty line. Poverty, according to T.V. Hovorun, affects families, and their lives, planning life on "daily stresses", which correlate with many negative manifestations-lag, in the ability to learn in the first place. The lack of cognitive skills has been documented in psychological studies in children from poor families since 3-4 years. The economic problems of parents from poor families affect the attitude towards their own children: they are either authoritarian, more annoyed with the needs of their care, aggressive in situations of expert examination of the conditions of development, much more adept at behaving the young, arrogant and punishing the slightest fault, do not even satisfy basic needs of the child. Or much more often, choosing ignorant, ignoring the style of education, indifferent not only to any needs and interests of children, but also to their illnesses or successes, manipulate them, do not concern themselves with behavior, nutrition, dress, well-being and, even, a long absence children at home. Both those who are incapable of normal care and care of children, empathy communication with them, satisfaction of both their biological and social needs, indifferent to their vital activity in general. They are more likely to exhibit negative emotions about the world around them, their neighbors, teachers, and more often they oppress children by applying their physical and mental punishment, which in aggregate can not but affect the asthenic or giperastenicheskih mental states of children.

Consequently, an economic factor, along with others, in the first place predetermines the unfavorable psychological climate of the family,

\footnotetext{
${ }^{13}$ Hovorun T.V. Basic preconditions for the emergence and re-socialization of children and young people at risk groups / T.V. Hovorun // ScienceRise. - 2015. - No. 8 (1). - P. 84-89. - Access mode: http://nbuv.gov.ua/ UJRN/texc_2015_8(1)15
} 
pathological styles of family upbringing. The experience of relative economic deprivation and frustration plays the role of a trigger mechanism, which begins to spread its destructive effect on the birth and development of abilities and all those personal components that determine the norm of mental development. It becomes sufficiently significant in causing the risk of personal development primarily to children of immigrant families, refugees, single, large families, national minorities, and minors.

The connection between the living conditions and the upbringing in the family and the type of personality of the child was also revealed in the researches of N.I. Nepomnyaschaya. According to the results, in the families of children with a valuable background of real-life functioning, the lowest type of relations, "I am different", one of the leading values is often considered material well-being, adjusted life, as a rule, reigns the cult of real, practical, and not personality relations. Therefore, the child, its achievement parents evaluate in terms of not only her personality, but the result achieved. The prevalence of close negative assessments that accumulates the experience of failures leads to the fact that many children in this group lack independence, they are unsure of themselves, often feel fear, show negativism, conflict, inadequate perception of behavior and attitude towards themselves from other children ${ }^{14}$.

In families with universal values (but these children, unfortunately, they form a minority), children are raised with the highest type of relations "I am different", with a high level of development of the ability to "be myself and another one" with high indicators of overcoming the limited perceptions of the world and ourselves, the development of consciousness and activity. Many tales tell children in such families, at home they play with them a lot, games and toys change from time to time, and children often invent their new games themselves. Characteristic for these families is also the openness of the family to people, different interests, diverse and new affairs, they have family traditions, produced a home newspaper, etc. All this forms in children a desire for an interesting (in all spheres), new, perfection, creative attitude to any business.

\footnotetext{
${ }^{14}$ Nepomnyaschaya N.I. Formation of the personality of the child 6-7 years / N.I. Nepomniachaya // Scientific research. Institute of General and Pedagogical Psychology Acad. ped Sciences of the USSR. Moscow: Pedagogics, 1992. - 180 p.
} 
As a rule, in families, which distinguishes openness to various interests, affairs, people, the diversity of forms and content of communication with the child, the attention to other people, care for them, responsible and personal attitude to various activities and assessment through such an attitude of the child's personality, every kind of promotion of love for games, recognizes the high value of education, gifted children are brought up. Parents pay special attention to teaching their child, choosing for her books, manuals, educational games, etc. Children and parents combine common cognitive interests, on the basis of which there are stable friendly relations. Home, virtually obligatory feature of the family of any gifted child - unusually high attention to the child. Adult support leads to the consolidation of certain forms of behavior, the reaction of parents determines the further development of abilities and talents of children.

That is, family interaction, communication is through the formation of personal orientations that determine the vital "trajectory", a vector of development abilities. His construction stimulates the relationship between children and adults, joint games, walks, classes, reading fiction, and excursions with them in nature. In general, the promotion and support of aesthetic, moral needs contributes to the formation of a personality and value foundation for the development of abilities; the formation of volitional qualities and emotional processes, provides a motivationalvolitional aspect of the development of abilities.

The dynamics of the formation of all components of the development of abilities, the acquisition of cognitive, social experience, the stock of children's knowledge in the majority depends on how the parents provide the child with meaningful cognitive communication, support hobbies, interests of the child, offer various cognitive, developmental sources and incentives, create an educational, educational environment.

Only the family, father and mother, who are aware of all responsibility and significance of family interaction, are fully capable of providing the necessary conditions for a developing environment for the development of the child's personality and the flowering of her abilities. The family puts the foundations of personality, its future, formed motivational-volitional, cognitive-creative, personality-value and operational components of abilities. The family, where the child gets maternal care, the support of his father, where love and authoritative style of education reigns, a person is born and growing. 


\section{The basis of the formation of conscious paternity}

Formation of the person takes place in the presence of a favorable development environment, in the conditions of family education and partner interaction. The decisive factor in the development of a child is the presence of a meaningful adult in the immediate surroundings. In communication with adults and under their constant guidance and influence, the child is gradually mastering a variety of activities, skills, and developing his abilities. But, unfortunately, today one of the acute problems is the issue of the lack of formation in the youth of readiness for family life, the birth and upbringing of children as conscious, responsible parents.

Today, there is a typical problem of avoiding the traditional division of roles in the family, devaluation of family values and traditions, reducing the level of family stability, spreading orphanage, feminization, and other relevant phenomena in the field of family psychology, child-parent relationships. That is why the subject of psychological research focuses on the study of the problem of conscious (conscious), responsible fatherhood. "Fatherhood", as a social and pedagogical phenomenon, includes a set of paternal features, feelings, knowledge and skills of child development to ensure the formation of a healthy and mature person, starting with childhood. This phenomenon is the subject of interdisciplinary research, is studied within the framework of not only psychological, but also social, pedagogical and other sciences, which initiate the development of scientific approaches and measures of social and psychological patronage of a young family. Informational education of future and young parents, raising the level of psychological and pedagogical competence of specialists working with young people, as well as integration of services of social-pedagogical, psychological and specialized support of young families are an important prerequisite for family well-being and full-fledged development of childhood.

It is worth emphasizing that scientists consider conscious, responsible fatherhood as a socio-psychological phenomenon based on a certain system of knowledge, skills, skills, feelings, qualities that are realized in the responsible behavior of parents, aimed at the upbringing and development of the child, the formation of her harmonious personality. Conscious paternity is the highest level of parenting competence, which is characterized by a combination of cognitive (knowledge) and behavioral (skills, skills, actions) systems. In the context of the cognitive component, 
in the first place, parents must have knowledge of the laws of the age-old mental and physiological development of children, of parental functions, needs of the child; on the optimal organization of the child's life in the family; the specifics and conditions of the formation of abilities during childhood; to understand the values of family life and family upbringing. Valuable orientations are an important factor for the family, both at the level of interaction between the spouses, and at the level of interaction between parents with children. These include such values as love, health, healthy lifestyles, family and cultural-national traditions and customs. Parents should also have the knowledge and knowledge about problems, typical family education failures and ways to eliminate them. Such mistakes include: underestimation of a personal example of parents (parents translate values to children, but do not support their own behavior); assigning children the qualities they do not own or exaggerating them; incorrect behavior of individual parents in everyday life; inability to use methods of education, especially encouragement and punishment; removal of children from forced domestic work; the lack of unity of requirements in the parent's educational activities; absence of tact in relations with the child; revaluation by parents of their educational opportunities; application of physical punishment; quarrels of parents in the presence of children, etc.

Important in the structure of conscious fatherhood is the operational component, which implies the possession of certain skills for the successful implementation of conscious methods, techniques, forms of education, training and self-development, self-realization of the child's personality. This component can be realized in the ability to organize the lives of children, to diagnose their abilities, interests and inclinations, to encourage and develop them, creating favorable conditions for this. This is, in particular, the ability to constructively communicate and resolve conflicts; organization of family-friendly interaction, child's activity; construction and implementation of a unified system of values; the optimal psychological and pedagogical environment surrounding the child in the family; skills of humanistic upbringing of the child. Also valuable is the creative component that allows parents to creatively use their own knowledge and skills in educational activities, based on the conditions in their family, to build an event series, as well as to use advances in the field of pedagogy and psychology. 
At the advanced stage, parenthood includes parental values, attitudes and expectations, parental attitude, feelings, parental responsibility, parental responsibility, as well as the style of family upbringing, which involves observing the principles of family education, which are permeated with the humanistic idea of the highest value of the child, namely : children should grow up and be brought up in an atmosphere of benevolence, love and happiness; parents must understand and accept their child as it is, and promote the development of a better one; Educational influences must be based on age and individual characteristics; the dialectical unity of sincere, deep respect for personality and high demands on it should be the basis of family upbringing; the identity of the parents themselves - an ideal model for the imitation of children; education should be built on the basis of positive foundations in a growing person; all activities that are organized in the family for the development of the child must be built on the game; optimism and positive - the basis of style and tone of communication with children in the family.

Generally, conscious parenting is the interaction of parents or individuals who replace them, among themselves, with other family members, including children, which results in the creation of the most favorable conditions for the full, harmonious personal and social development of the child at all stages of her life. Conscious paternity based on family interaction, which activates cognitive, productive activity, supports interest and motivation to it, stimulates the development of the personality-value, cognitive-creative sphere is a necessary factor in the manifestation of abilities and the formation of the gifts of the child.

In this context, the negative factors of family education that hinder the formation, development of the child's personal potential are: the priority of material well-being over the realization of the spiritual needs of the child; lack of spirituality of parents, lack of desire for personal development of children; authoritarianism or liberalism; immoral style and tone of family relationships; absence in the family of a normal psychological climate and pedagogical culture of communication; illiteracy in the psychological and pedagogical relation (lack of purposefulness of education, unprincipled, contradictory in the application of methods of education, physical punishment, infliction of children of severe moral suffering), etc.

With the preventive and correctional purpose of forming a conscious, responsible parenthood, you can use a variety of activities: the development of information leaflets, monuments; conducting of seminars, 
trainings, round tables; organization of mutual support groups; the work of the "Telephone of Confidence" service, an advisory point; realization of programs, including classes with future, young parents. The main goal of all these measures is to popularize the idea of a responsible one. conscious paternity as an indispensable condition for the harmonious development of the child. The growth of the level of pedagogical literacy of parents increases the positive developmental interactions in the family, which affects the development, behavior of the child and promotes the growth of his abilities.

Thus, responsible, conscious parenting, which is a system of knowledge, skills, skills and experience in the field of child upbringing, willingness and ability of parents to responsibly solve vital problems for the family, is an important prerequisite for the development of personality in childhood.

\section{Program of socio-psychological support of paternity}

Nowadays, the problem of paternity is acute not only in terms of the demographic situation of fertility, but also in the context of the negative socio-psychological problems of the formation of a harmonious personality. Young parents who have become parents often do not realize all responsibility for their paternity duties, do not have a set of necessary competences in the field of paternity, become hostages of their own problems in raising children and family relationships.

Responsible, conscious paternity manifests itself in the general culture of the individual's parents, its qualitative characteristics, the degree of readiness for the upbringing of the future child. The opposite of conscious and responsible fatherhood is the phenomenon of deviant motherhood / parenthood, which is often accompanied by an aggressive attitude of the mother or father to the child. The program of "uselessness" destroys the child's psyche even in the fetal period and increases during the early childhood by careless, disrespectful attitudes. This once again proves the necessity of forming sense of conscious and responsible parenthood in modern youth.

We are convinced that during the planning period, the expectation of the child and her early childhood, the family needs professional social and psychological support, support aimed at creating a favorable psychological climate in the family to reveal the emotional, intellectual and social potential of the family as a whole, taking into account the individual and 
age characteristics of the child, the prevention of mental disorders and deviations in her behavior. And, paraphrasing Bismarck, we would remark that if today we do not "build" schools of fatherhood, then tomorrow we will have to build prisons.

All of the above has led us to develop a special program of psychological and pedagogical support for married couples aimed at the formation, prevention and correction of effective family interaction, the formation of a democratic style of family education, the community of "child-adult", a developing environment. The program indirectly declares the values of family and parenthood in human life; informs about the ethics and psychology of family life, effective parenting behavior; forms responsible attitude towards parental functions; develops dialogic communication skills; promotes self-realization and self-realization in the conditions of the family.

In addition to individual consultations, the program involves conducting a training course, which includes four courses: "Readiness for marital life", "ABC of family communication", "Understanding of one's own life", "Conscious parenthood". Each course includes a series of exercises, the sequence and duration of which is determined by the coach. An integral part of this curriculum and in fact every class is an exercise in which participants can share their thoughts and feelings, their successes and failures.

\section{Lesson 1. Readiness for married life}

Exercise "My Name"

Exercise is performed in a circle, each participant names his name and answers the question:

- Who and why gave you name?

- Do you like your name?

Exercise has a reflexive goal - participants turn to their past, recall the history of their name, which has roots in the family.

Exercise "Brainstorming"

Participants discuss the issues:

- What is the perfect family? motherhood?

- What factors influence the formation of parenthood and

It should be borne in mind that hierarchically all factors that influence the formation of family, parentage and maternity can be placed at the following levels: 1) level of society, 2) level of parent's family, 3) level of 
their own family and 4) level of specific personality. Society gives a person a model of paternity, which initiates the formation of paternity in each particular case, taking into account the peculiarities of the spouses, their value-motivational sphere and the experience gained in the parent's family.

\section{Exercise "Associative Chain"}

On the board, the leader divides the sheet into three columns with the names: "Family", "Parents", "Child".

Participants are asked to pick up one word association associated with these concepts and write in their workbook. Then alternate voice their associations to these concepts, and the presenter writes them in the corresponding column on the board, creating a kind of associative chains.

The host invites participants to select any of the named associations and combine them with the other, the most successful, in his opinion, from the proposed.

Subsequently, by grouping together, they work on defining each concept based on the corresponding associative chains. Then the groups present their definitions in a large circle.

Discussion Questions:

- Why it was necessary to determine the meaning of the concepts of "family", "child", "parents".

- Did assimilation words help to define the concepts?

Exercise "Myths and Reality"

Often young people who enter into marriage and those who are already married have a poor understanding of the family. The reasons for this can be diverse: the lack of a sample of normal relationships in the parent's family, social deprivation, indifference, selfishness, etc.

All turn out to be an example of their own lives in relation to the "myths of married life" and discuss its "myths and reality".

Questions that will encourage listeners to share their thoughts.

- What are your hopes and expectations about the role of husband or wife and how do they come about?

- What model of marital life have you observed in your parents' family, what would you like and do not want to move to your own?

- How do you spend time in a family circle?

Exercise "Family Responsibilities".

Participants are offered a list of possible family responsibilities that need to be shared between husband and wife. 
Approximate list of responsibilities: washing dishes, washing a car, home repairs, repairing clothes, gardening / gardening, home cleaning, buying food, cooking, washing, making money, making purchasing decisions, caring for a child, raising children, planning leave, home accounting, etc.

Exercise "On the threshold of the family".

The exercise is aimed at actualizing possible conflicts that may arise when creating your own family. Each participant receives a situation card / task and announces his version of the solution.

List of approximate questions:

- How would you treat jealousy from your loved one?

- Who will take care of the child, for which help you wait?

- Does the father have the right to an equal (or decisive) vote in matters of raising a child?

-What way to use for saving money?

- How will you react if your wife does not cook tasty and monotonous?

- Can relatives interfere with your relationships and lifestyles?

- Can friends stay for you to sleep?

- How will you treat the bad habits of your halves?

Exercise "Tree of Family Values"

In this exercise, it is necessary to receive the procurement of "Trees of Family Values" and a list of possible family values and to diagnose them. In the root system to put the most important values from which you do not want to refuse under any conditions; in a trunk - important, but from which in some cases it is possible to refuse; in the crown - desirable but not obligatory values.

List of family values: respect, care, sincerity, kindness, patience, courage, diligence, financial security, health, love, mutual understanding, common goals, family traditions, hobbies, education, communication between generations, etc.

Exercise "Family History"

Participants talk about an item that has long been stored in their family and is its relic and pride. It could be a photo of grandfather, grandmother, inherited book, old paper or reward. Think you leave your children inherited?

Exercise "Ingredients for strengthening the family"

All participants write an idea that, in their opinion, promotes the strengthening of the family and the establishment of relationships with 
children, attaching it to the board. Then the presenter alternates with the idea and collects the analysis together.

\section{Exercise "Candle"}

The participants become in a circle, transmit a candle in a circle and speak warm words, compliments, gratitude to each other.

\section{Lesson 2. Alphabet of family communication}

Exercise "Association"

Participants are invited to continue the sentence:

1) If the family is a building, then it ... (fortress, tent, hostel, ...);

2) If the family is a color then it ...;

3) If the family is a music, then it (the play on the violin, metal, cacophony, ...);

4) If the family is a geometric figure, then it ...;

5) If the family is the name of the film, then it ...;

6) If the family is a mood, then it ... (stress, calm, ...).

Exercise "Maps"

Each participant picks out a deck of cards that depicts scenes from his family life and tells which scenes he is enjoying, and which ones he does not want to repeat.

Exercise "Comparison of Values"

Participants list: a) the most significant values of their partner; b) their significant values.

Subsequently, familiarize them with their partners, compare their values with the vision of their partner. What would you like to change in these lists?

\section{Exercise "I-utterance"}

Young people write on a blank sheet for a flipchart notebook: "I'm worried", and they continue sentences several times ...

This way helps to relieve tension in the situation and encourages another person to pause and listen. In order to properly use the "Imessage", we need to know what we feel, and then simply and honestly say about it.

Gradually, parents learn to change "You-message" to "I-message": train the skills and try to turn "You-message" to "I-message" on specific examples.

Exercise "You are the most ..."

Participants in pairs in turn call the positive qualities of each other, starting with a sentence from the words: "You are the most ...". 


\section{Exercise "Request and Requirements"}

Sit alongside a partner. Ask him about anything in a demanding form. What do you feel when you ask and find out what your partner feels at the same time.

Now ask for something, expressing your feelings (recalling merits, emphasizing authority, using compliments), asking and listening. What does the other feel?

\section{Exercise "Your Exit"}

Each member of the group speaks to the group twice (it can be a poem, song, dance) - once the group demonstrates its inattention (sit back, talking, yawning, etc.), and the next time - active attention and interest. Speaker, speaking, compares his feelings.

Exercise "Ask"

The group is divided into pairs, in the hands of one of them a toy, which he can give only if he wants to. The one who asks must use all the different ways of influence: orders, persuasion, persuasion.

In the discussion, it's important to find out: What is the most effective in communicating? How to communicate in order to achieve its goal?

Exercise "Learn to listen"

In a circle, each participant has to repeat what the participant has said on the right, and add something from himself. The third one should repeat the phrase of the first, the second participant and add something to his own, etc.

\section{Exercise "Drawing by instruction"}

The pair sits back to each other. One of them receives a card depicting geometric figures in different combinations. His task is to instruct the other partner so that he can reproduce the image of the card. The one who draws: a) can ask clarifying questions; b) can not communicate with a partner.

Exercise "Family Contract"

Participants record points that determine, in their opinion, the rights and responsibilities of partners in their family. The discussion is based on the example of one family.

\section{Lesson 3. Understanding your own life}

Exercise "About Me"

Participants are asked to find a partner and answer questions (a list of questions, written on a sheet of notebook for flipchart):

- What can you say about yourself when you were five years old? 
- How did your parents name you?

-What do you think your parents would describe you at that age?

-What childhood memories are most vivid?

-What was your favorite toy and game?

- What kind of movie hero, fairy tale or heroine can you identify yourself? Why?

- What is your favorite book? What does it mean for you?

- Which of your family members are you most alike to? Why?

- What of your own childhood would you like to happen in the life of your child? (Remember and tell about the best moments of your childhood).

These questions and other questions can be discussed in small groups as well.

Exercise "Autobiographical essay"

Participants sit in a circle and orally present their autobiographical essays; share important life experiences, accumulated from childhood till now. This experience should be important in the sense that it has a strong influence on the formation of each individual.

Exercise "If I Were a Child..."

Imagine what it would be if you for a moment became a child ...

What would you like to do in this situation? What activity would you do with whom you would like to communicate with, etc.?

Exercise "Self-examination"

Invite participants to tell you about yourself in the format of good news / bad news, what is going on and what does not happen in your life. Why still need to learn what knowledge and skills to get to be prepared to give attention and care to others?

\section{Lesson 4. Conscious Paternity}

A child needs a love and understanding for a complete and harmonious personality development. He should, whenever possible, grow up under the care and responsibility of her parents, and in any case - in an atmosphere of love, moral and material security. Declaration of the Rights of the Child, 1959.

Exercise "Child"

Give the definition of the word «child»: «The child is ...»

When discussing the emphasis is on positive definitions. 


\section{Exercise "My child".}

Parents should tell at their request:

- What are your children's names and why did you decide to choose them (names)?

- What kind of activity do you like to do with a child (what kind of toy to play, what book to read, etc.)?;

- What do you most like in your child?

Each of the parents must complete one of the following sentences:

"Two words that can describe my child are - ....";

"If my child was sound, then it would sound like ....»;

«My child makes me laugh when ...".

Exercise "Tree of Conscious Paternity"

Participants represent a conscious parenthood in the form of a tree:

The roots and basis of the tree are the definition of "conscious parenting";

The tree branches that form the crown are:

a) branch of knowledge - knowledge that will help parents in the development and upbringing of the child;

b) the branch of feelings - the feelings of parents in relation to their children;

c) a branch of abilities - skills that help parents to successfully perform the function of paternity and which should be owned by their parents;

d) a branch of qualities - features of character that should be inherent in conscious parents.

Exercise "The image of a happy child"

The leader offers using a sheet of watman, newspapers, magazines, threads, cloth, scissors, colored paper, glue, markers, create a collage: "The image of a happy child" and prepare a commentary on the result of the work for presentation. After group presentations, the psychologist draws attention to the fact that one of the components of the happiness of the child in the family is the presence of parents. He brings to mind that parents are happy when a happy child.

Exercise "Types of communication"

Parents are asked to compile a list of ways in which the child communicates with adults.

Answers are written on a sheet of notebook for the flipchart. They can be: crying (different kinds); movements; visual contact; eye tracking for 
objects, objects; smile; squeak; turning the head toward the mother (father); sucking (self-complacency); agoughing babble; conversation, etc.

It is important to pay attention to the importance of all ways of communication.

Exercise "Communication Style"

The participants are grouped into four groups, each group receives a card with a characteristic of one style of behavior.

Card 1. Authoritarian style of parenting behavior

Parents who are prone to authoritarian style:

- too hard;

- apply physical punishment;

- excessively control all child's actions;

- Demand from her constant obedience;

- Restrict the right to choose a child;

- do not want to compromise with the child;

- intolerant of childhood disadvantages and manifestations of «childhood».

Card 2. Liberal style of parenting behavior

Parents who are inclined to liberal style:

- exercise little control over the behavior of the child or control at all absent as a result of indifferent attitude towards the performance of parental responsibilities;

- practicing permissiveness;

- fulfill all the wishes of the child;

- unjustifiably idealize their child.

- How does a child feel to his parents in this way?

- How can parents' attitude to the child affect their personal development?

At the end, each group reads a behavior style card and offers a general review of the results of its considerations. After this, the leader gives parents the task of determining which parenting behavior is most conducive to the child's personality.

Exercise "Settings"

Parents analyze how often do they speak to children?

- Everything will happen to you!

- You are strong, do not give up!

- Thank you for helping!

- I'm on your side! 
- I'm proud of you!

- I love you!

- I am glad for your success!

- Everyone may be wrong, try again!

- Everything in life depends on you!

- I'm glad to see you!

«It's good for me when we're together ...!

- I like how you ...

"Come on, let's do it ..." together.

-You're so good!

It is discussed that most of the settings that children receive from their parents, further determine their behavior, is a guide to their personal development.

Give your parents a few minutes to exchange their thoughts in pairs.

What experience do you need to pass on to your child so that your dreams come true? What will you start with?

\section{Homework}

1. Analyze how you manage to understand your child. To do this, during the day (or preferably 2-3 days) try to count how many times you turned to him with emotionally positive statements (joyful greetings, approval, support, praise), hugged themselves, listened carefully, put their hands on their shoulders, rejoiced with together she was given a feeling that she loved her; and how many times you were angry, forbidden, remarked, punished, threatened, criticized, treated reproach. Would you like to be in the place of your child?

If the number of negative hits is equal to or exceeds the number of positive ones, then you are not all happy with communication and you should think about why one should praise the child, which statements to avoid.

2. Follow the emotions of the child. Fix the reactions of sympathy and antipathy and analyze what causes them. This will develop the habit of being careful and notice changes in the behavior of the child.

3. Close your eyes for a moment and imagine that you meet your best friend (or girlfriend). How do you show that he is glad that he is dear and near to you? Now imagine that this is your own child: here he comes home from school and you show that you are glad to see him. Imagined It's now easier for you to do this in real life, without any other words and questions. 
4. Embrace your child at least four times a day (ordinary morning greetings and kisses at night are not counted).

5. When performing the two previous tasks, pay attention to the reactions of the child and their own feelings.

6. Make a list of all kinds of behavior - actions and words that you regularly broadcast to the world (many laugh, laugh, do exercises, emotionally unstable, sit on the Internet). Discuss them with your husband, wife. Are there a lot of things you can be proud of? Circumvent the behavior (actions) that you would like your children to copy from you. Practice it regularly. Gradually eliminate your unwanted behavior.

7. Write the letter to yourself.

\section{CONCLUSIONS}

Thus, the program provides the opportunity to obtain the necessary information about the peculiarities of the upbringing of the child, the existing problems in relations with the child, as well as obtain their own experience of their solution. The result of participation in the program should be the construction of their own parenting position, changing the attitude towards the child - from awareness of themselves and the child as a unified system, to recognition of the child as an individual, who has his own subjectivity, as well as the construction of a system of communication with her as an equal partner on a trust basis.

There is no doubt about the therapeutic value of the program, as participants get a new idea of themselves and their families, develop their parenting skills, which contributes to their personal growth. Because of this, the program helps not only the integration and strengthening of the adult self, the development of a sense of confidence in their own emotional and behavioral manifestations and the ability to manage them, but also the awareness of life scenarios and personal meanings and values, in particular, awareness of the importance of the family, family values, the new integral entity of personality - paternity.

\section{REFERENCES}

1. Ponomareva-Semenova R.A. Methodological aspect of developing a psychological model of an extraordinary personality // Current problems of psychology: Volume 6. Gifted personality: search, development, help. (collection of scientific works). / Under the editorship of S.D. Maximenko. - K. "BONA MENTE", 2002. - Vip. 3. (Part 1) - P. 226-236. 
2. Subbotsky Ye.V. The child opens the world: Kn. for the child's teacher. the garden / E.V. Subbotsky. - M .: Enlightenment. - $1991-207$ p.

3. Druzhynin V.N. Psychological abilities / V.N. Druzhynin.St. Petersburg: Publishing House "Peter", 2000.- 368 p. : (Series of "Masters of Psychology").

4. Medina John. Rules for the Development of the Child's Brain / John Medina. - K . : Our format. 2015.

5. Leshaft P.F. Family medicine peder / P.F. Leshaft. - Moscow: Pedagogics, $2014-224$ p.

6. Druzhynin V.N. Psychological studies / V. Druzhynin. - Moscow: "KSP", 1996, 160 p.

7. Lisina M.I. Problems of ontogenesis of communication / M.I. Lisin // Scientific research. Institute of General and Pedagogical Psychology Acad. ped Sciences of the USSR. - Moscow: Pedagogics, 1986. - 144 p.

8. Hippenreiter Y.B. Communicate with the child. How? / Y.B. Hippenreiter, - Moscow : CheRo, 2001. - 240 p. : il.

9. Bern E. Games in which people play // E. Bern - Exmo, 2003. $576 \mathrm{p}$.

10. Schneider L. B. Family: Looking Back / L. B. Schneider. - SPb. : Peter, 2013. - 368 pp .: Il. - (Series of "Masters of Psychology").

11. Hovorun T.V. Basic preconditions for the emergence and resocialization of children and young people at risk groups / T. V. Hovorun // ScienceRise. - 2015. - No. 8 (1). - P. 84-89. - Access mode: http://nbuv.gov.ua/UJRN/ texc_2015_8(1)15

12. Nepomnyaschaya N.I. Formation of the personality of the child 6-7 years / N.I. Nepomniachaya // Scientific research. Institute of General and Pedagogical Psychology Acad. ped Sciences of the USSR. - Moscow: Pedagogics, 1992. - $180 \mathrm{p}$.

13. Bila I.M. Model of development of abilities at the childhood stage / Actual problems of psychology: a collection of scientific works of the Institute of Psychology named after H.S. Kostiuk, 2017, Vol. VI, Psychology of Giftedness, Vip. 13, pp. 20-31.

14. Hroff S. Outside of the brain. Birth, death and trans-centency in psychotherapy / S. Hrof. - Moscow: AST, 2005. - 495 p.

15. Rubinstein S.L. Abilities // Psychology of Individual Differences / ed. Yu.B. Gippenreiter, V.Ya. Romanova. - 3rd ed., Pererab. and add Moscow: AST: Astrel, 2008. - P. 31-46. 
Information about the authors:

Bila I. N.

Candidate of Psychological Sciences, Associate Professor at the Department of Psychology and Pedagogy of the V. I. Vernadsky Taurida National University 33, Ivana Kydri str., Kyiv, 01042, Ukraine 